\title{
Intensificação do trabalho e saúde dos
}

trabalhadores: um estudo na Mercedes Benz do Brasil, São Bernardo do Campo, São Paulo' Work intensification and workers' health: a case study in Mercedes Benz of Brazil, São Bernardo do Campo, São Paulo, Brazil

\author{
José Augusto Pina \\ Fundação Oswaldo Cruz. Escola Nacional de Saúde Pública. Centro \\ de Estudos da Saúde do Trabalhador e Ecologia Humana. Rio de \\ Janeiro, RJ, Brasil. \\ E-mail: augustoळensp.fiocruz.br \\ Eduardo Navarro Stotz \\ Fundação Oswaldo Cruz. Escola Nacional de Saúde Pública. \\ Departamento de Endemias Samuel Pessoa. Rio de Janeiro, RJ, Brasil. \\ E-mail: stotzœensp.fiocruz.br
}

\section{Correspondência}

José Augusto Pina

Avenida Leopoldo Bulhões, 1480. Rio de Janeiro, RJ, Brasil. CEP 21041-210.

\section{Resumo}

Na sociedade contemporânea, a intensificação do trabalho representa, cada vez mais, um mal-estar, manifesto em problemas de saúde dos trabalhadores. Como problemática da Saúde Coletiva/Saúde do Trabalhador, o objeto "intensificação do trabalho e saúde” pode ser estudado nas práticas específicas de exploração e expropriação do conhecimento técnico e social do trabalhador tendentes a confrontar sua capacidade coletiva, visto que o enfraquecimento da dimensão coletiva está a desencadear múltiplas manifestações de sofrimento e penosidade no trabalho. Neste estudo, analisamos o processo de intensificação do trabalho e saúde a partir da percepção dos trabalhadores da Mercedes Benz do Brasil, em São Bernardo do Campo. Realizamos sete visitas à fábrica e vinte e nove entrevistas: vinte e duas com trabalhadores diretos e sete com representantes sindicais. Os resultados e a discussão são apresentados em três categorias: ritmo de trabalho, prolongamento do trabalho, e administração por estresse. 0 estudo contribui para o avanço do entendimento da intensificação do trabalho e saúde e, ao mesmo tempo, traz indicações sobre os limites e as possibilidades postos à ação coletiva dos trabalhadores nas atuais condições históricas.

Palavras-chave: Intensificação do Trabalho e Saúde; Saúde do Trabalhador; Ação Coletiva dos Trabalhadores; Administração por Estresse; Penosidade no Trabalho. 


\section{Abstract}

In contemporary society, work intensification has been increasingly representing a malaise that manifests itself in workers' health problems. As a theme studied by Public Health/Workers' Health, the object "work intensification and health" can be investigated in the specific practices of exploitation and expropriation of workers' technical and social knowledge that tend to confront their collective capacity, as the weakening of the collective dimension triggers multiple manifestations of suffering and penibility at work. This study analyses work intensification and health based on the perception of workers from Mercedes Benz of Brazil, in the city of São Bernardo do Campo, São Paulo. We conducted seven visits to the factory and twentynine interviews: twenty-two with direct workers and seven with union representatives. The results and discussion are presented in three categories: work pace; longer working periods; management by stress. The study contributes to the understanding of work intensification and health and, at the same time, indicates the limits and possibilities imposed on workers' collective action in the current historical conditions.

Keywords: Work Intensification and Health; Workers' Health; Workers' Collective Action; Management by Stress; Penibility at Work.

\section{Introdução}

Na sociedade contemporânea, a intensificação do trabalho representa, cada vez mais, um mal-estar, manifesto em problemas e agravos à saúde dos trabalhadores. Trata-se de um processo histórico e social de abrangência global em inúmeras atividades produtivas (indústria, comércio ou serviço). Na Europa, o estudo dessa problemática abrange diferentes campos de conhecimento científico, inclusive a área da saúde (Askenazy et al., 2006).

No Brasil, a rigor, intensificação do trabalho e saúde ainda não constitui um objeto de estudo estruturado na Saúde Coletiva/Saúde do Trabalhador, embora alguns de seus possíveis contornos apareçam entre os resultados de pesquisas nesta área.

Comumente, intensificação do trabalho é definida como aumento da intensidade do trabalho. É o caso de Dal Rosso (2008) ao centrar seu entendimento na maior quantidade ou na maior qualidade dos resultados do trabalho no mesmo tempo. Em outro trabalho (Pina; Stotz, 2014), chamamos a atenção para os problemas em situar o entendimento da intensificação unicamente em termos de magnitude e como um resultado, pois conduz a investigação a estudar dois momentos isolados no tempo. Isto é, para saber se o trabalho atual em relação a um determinado momento anterior (um, dois, três anos antes ou em comparação ao primeiro trabalho) tem mais, menos ou igual intensidade, expresso em termos de horas trabalhadas, ritmo, acúmulo de tarefas, flexibilidade, entre outras categorias. E, a partir da comparação entre esses dois momentos, identificar e estabelecer conexões com os efeitos deletérios em termos de danos à saúde. No entanto, esse procedimento pode obstruir ou ofuscar o estudo das características concretas do processo de intensificação do trabalho e suas implicações na saúde.

Ao considerar a intensificação do trabalho como uma dimensão social particular da exploração capitalista, distinta da produtividade e do prolongamento do trabalho, o que destacamos é o processo contraditório pelo qual se produz e se obtém o maior quantum de trabalho por unidade de tempo (Pina; Stotz, 2014). Também, na direção do estudo etnográfico e histórico de Hatzfeld (2004), trata-se de um contínuo processo de expropriação/apropriação 
do "saber prático" do operário pela gerência, isto é, das capacidades físicas e intelectuais do trabalhador. Expropriação/apropriação é entendida como processo contínuo de assimilação do aprendizado coletivo dos trabalhadores pela gerência para vencer a resistência e, tanto mais, obter a mobilização operária, tal como formulada por Marx (1984, p. 8o): "só a experiência do trabalhador combinado descobre e mostra como e onde economizar, como efetivar de modo mais simples as descobertas já feitas, quais os obstáculos que precisam ser superados na efetivação [de] sua aplicação no processo de produção”.

Quer dizer, a intensificação está enraizada em práticas de exploração e expropriação que afetam o trabalhador no processo de trabalho. Isso denota a complexidade do processo intensificação do trabalho e saúde enquanto objeto de estudo. Pois, de um lado, encontramos uma diversidade de dimensões do processo de trabalho implicadas na intensificação, tais como: o ritmo de trabalho (Gollac; Volkoff, 2007), as formas de reorganização do tempo de trabalho (Pina; Stotz, 2011), a gestão por performance (Bártoli; Rocca, 2006), ou a administração por estresse (Parker; Slaughter, 1995), isto é, o estresse como instrumento de gestão para manter a pressão permanente sobre os trabalhadores.

De outro lado, há uma pluralidade de problemas e agravos à saúde implicados na intensificação, manifestos em: acidentes de trabalho (Fairris; Brenner, 2001), lesões por esforço repetitivo/distúrbios osteomusculares relacionados ao trabalho (LER/DORT) (Fernandes; Assunção; Carvalho, 2010), transtornos psíquicos e problemas cardiovasculares (Deriennic; Vézina, 2006); também em sofrimento e penosidades pela violência das práticas de gestão ou pela degradação da qualidade do trabalho afetar a identidade profissional (Davezies, 2007).

Na atualidade, a penosidade emerge da dificuldade dos indivíduos em lidar e acompanhar as seguidas injunções que redefinem seu trabalho. Linhart (2011) refere-se à desestabilização dos coletivos e dos valores comuns dos assalariados para conter ou acomodar os esforços e os desgastes. Pela experiência histórica dos trabalhadores, os coletivos podem reduzir o sofrimento e o desgaste tanto pela ajuda mútua quanto por situá-los em relação à exploração e à dominação no trabalho, ou seja, ao conferir-lhes um sentido coletivo.
Em consonância, o objeto intensificação do trabalho e saúde pode ser definido e estudado pelas práticas específicas de exploração e expropriação tendentes a enfraquecer a capacidade coletiva do trabalhador para proteger sua saúde e para questionar as determinações dos problemas e dos agravos à sua saúde (Pina; Stotz, 2014).

Essa conceituação do objeto de estudo estimula a realização de pesquisas empíricas, pois delimita o campo da investigação e conta com abertura necessária para captar outros elementos do real, advindos, especialmente, da experiência dos trabalhadores. Uma montadora da indústria automobilística no Brasil é um lugar emblemático para esse estudo pelo peso estratégico que ocupa no desenvolvimento capitalista, nas ações do Estado e nas práticas de gestão da produção e da força de trabalho, com poder de difusão para diversos setores produtivos de bens e de serviços. E, destacadamente, pela importância política dos trabalhadores organizados no local de trabalho.

Esta pesquisa tem por objetivo analisar o processo intensificação do trabalho e saúde a partir da percepção dos trabalhadores da Mercedes Benz do Brasil, em São Bernardo do Campo, São Paulo (MBB/SBC). Ao refletir sobre o modo como os trabalhadores percebem o processo intensificação do trabalho e saúde, nosso propósito é examinar como as práticas de exploração e expropriação confrontam a capacidade coletiva do trabalhador, visto que a perda, o enfraquecimento ou a ausência do coletivo estão a desencadear múltiplas manifestações de sofrimento e agravos à saúde.

A escolha da empresa resultou da interlocução dos autores com diretores do Sindicato dos Metalúrgicos do $\mathrm{ABC}$ e da Comissão de Fábrica (CF) da MBB/SBC e com profissionais do Departamento de Saúde do Trabalhador e Meio Ambiente do Sindicato, devido a uma maior possibilidade de acesso ao local de trabalho e ao contato com os operários. 0 universo da pesquisa compreendeu os operários da produção direta na fábrica da MBB/SBC.

Embora este estudo não seja o resultado de uma pesquisa etnográfica, adotamos algumas de suas indicações: os atos de olhar, ouvir e escrever assumem um sentido "epistêmico" (Oliveira, 20oo, p. 18) e, em seu desenvolvimento, constituem atos cognitivos "disciplinados" pela definição de intensificação do 
trabalho e saúde como uma problemática no campo da Saúde Coletiva/Saúde do Trabalhador.

A coleta dos dados foi realizada de novembro de 2008 a julho de 2011. Os procedimentos metodológicos adotados foram, no trabalho de campo, a observação e a entrevista semidiretiva e individual com base em Bourdieu (1999). O trabalho de campo incluiu sete visitas à fábrica, todas guiadas pelos representantes sindicais. As visitas possibilitaram a coleta de informações sobre os acordos coletivos, a organização do processo de trabalho e a aproximação do ambiente socioespacial da fábrica (localização dos setores de produção, regras de convivência e a linguagem utilizada pelos operários). A entrevista aprofundou nossa incursão na realidade, acentuando os atos de olhar e, especialmente, de ouvir. Ao todo, realizamos vinte e nove entrevistas: vinte e duas com trabalhadores em atividade na linha de montagem (montador e líder de produção), usinagem (operador de máquina), funilaria (soldador) e manutenção (mecânico); e sete com representantes sindicais da CF. Todos os membros da CF estão integralmente liberados para o exercício da representação sindical no interior da empresa.

Na esteira de Oliveira (2000), a análise e a interpretação dos dados representam um permanente diálogo entre o objeto de estudo e o campo, conectadas no ato de escrever pelo qual se efetiva nosso pensamento na elaboração deste artigo. A interpretação dos dados resulta do cruzamento entre as estruturas de pensamento dos entrevistados e seu cotejamento com o referencial teórico-conceitual da Saúde Coletiva/Saúde do Trabalhador, apresentado nas categorias para a análise da intensificação do trabalho e saúde, a saber: ritmo de trabalho, prolongamento do trabalho e administração por estresse. Antes de sua apresentação, é importante situar o contexto das relações entre capital e trabalho no âmbito da empresa, uma vez que é nele que se dá o entendimento e a compreensão da percepção operária sobre o processo de intensificação do trabalho e saúde.

\section{A intensificação do trabalho e saúde na empresa}

A Mercedes Benz do Brasil inicia a produção de caminhões no país, em 28 de setembro de 1956, com a inauguração da fábrica em São Bernardo do Campo. Dois anos depois, teve início a produção de ônibus. É uma empresa do Grupo Daimler, sediado na Alemanha, um dos líderes mundiais na produção de veículos pesados. No Brasil, é líder na fabricação de ônibus e o segundo na de caminhões, em 2010, com participação de 57,9\% e 24,6\% da produção total, respectivamente (Anfavea, 2011).

A reestruturação da MBB/SBC, nos anos 1990, segmentou a planta industrial em quatro unidades produtivas: a fabricação de eixos, a fabricação de motores, a fabricação de cabines e a montagem final.

A modernização tecnológica foi inserida de forma desigual: bem mais ampla nas linhas de montagem do que na fabricação do eixo e do motor. Apesar da inclusão da automação e da robótica, as transformações produtivas se concentraram em inovações organizacionais e mudanças tecnológicas em equipamentos mais simples (Bresciani, 2001). A MBB/SBC ainda mantém uma grande participação da fabricação própria de peças e componentes utilizados na montagem de caminhões e ônibus.

A linha de montagem funciona como organizadora das demais unidades produtivas: o coração da fábrica. O lucro da fábrica, assim a denominou um representante sindical, em uma das visitas à linha de montagem de caminhões. A primeira expressão é o título do estudo de Vera Maria Candido Pereira (1979) entre os trabalhadores têxteis e ressalta o valor da memória histórica da classe operária. Indica a etapa mais importante do processo de produção, uma vez que todas as demais operações convergem para ela: na pesquisa da autora, a tecelagem; em nosso caso, a linha.

A gestão das mudanças na $\mathrm{MBB} / \mathrm{SBC}$, segundo Bresciani (2001, p. 9), representou a "inclusão institucionalizada e negociada" da participação dos trabalhadores diretos, mediada pela representação sindical no local de trabalho. A participação foi alçada a fator produtivo: de um lado, pela empresa, para minimizar as resistências e mobilizar o trabalhador em seu cotidiano de trabalho; de outro, pelo Sindicato, para manter o emprego e viabilizar a competitividade da fábrica.

Diversos acordos coletivos de trabalho foram firmados: Participação nos Lucros ou Resultados (PLR) (a partir de 1993); Terceirização (1994); Manufatura 
Celular (1994); Kaisen (1995); Trabalho em grupo (1995); Reestruturação salarial (1997); Contrato por tempo determinado (a partir de 1998); Redução da jornada de trabalho e banco de horas (BH) (1999). Esses instrumentos continuam incorporados à gestão da empresa e expressam a dinâmica assumida pela negociação entre as partes, inclusive no "chão de fábrica”, com salas da CF instaladas nas principais unidades produtivas.

Quanto aos rendimentos e benefícios: a remuneração média dos trabalhadores, em 2010, superou em mais de três vezes o rendimento médio dos assalariados da Região do $\mathrm{ABC}$ (Dieese, 2011). A empresa proporciona alimentação, ônibus até o trabalho, auxílio financeiro para o ensino superior, além de convênio médico e clube social e campestre para os trabalhadores e familiares. Cabe assinalar que a baixa rotatividade no trabalho (Dieese, 2011) possibilita fomentar entre os operários a perspectiva da ascensão profissional na empresa.

O entendimento sobre essas dimensões pode produzir manifestações na direção da identificação dos operários com a empresa (Markert, 1994), e as falas fornecem indícios neste sentido: a Mercedes é como se fosse uma mãe para mim. Trabalhar na montadora é representado como ganhar na loteria, quem entra, só sai na aposentadoria, um símbolo de status social: no centro de São Bernardo do Campo, algumas pessoas circulam com a jaqueta social da empresa, identificada pela estrela de três pontas. Isto é, a empresa pode ser tomada como horizonte. Com efeito, um trabalhador que manifeste a intenção de sair da MBB pode ser considerado, como relatam alguns operários, um louco.

Trata-se da transformação das condições de exploração e de dominação, com a produção de outras exigências ao trabalhador. Inclusive porque a representação sindical, assim como o próprio trabalhador, pode evocar a defesa da produtividade e empreender uma intensa mobilização para viabilizar seus resultados. Podemos considerar o papel ativo que tais práticas assumem na legitimação das exigências gerenciais tendentes a desorganizar os coletivos próprios dos trabalhadores. Como diz Lopes (1988, p. 32): "o vigor de uma forma de dominação pode ser avaliado por sua interiorização pelo próprio grupo dominado".
A participação sindical evoluiu e, atualmente, conta com uma instância semanal de acompanhamento da gestão da produção e da força de trabalho, chamada pelos sindicalistas de Quarta extra. 0 nome tem origem na reivindicação operária para redução da quantidade de horas extras, em que as negociações eram às quartas-feiras. Paradoxalmente, hoje, um dos temas da Quarta extra é a contratação das jornadas adicionais aos sábados, domingos e feriados, bastante numerosas com o crescimento da produção: somente em 2011, foram vinte e sete dias adicionais de trabalho.

Sem deixar de reconhecer as implicações das jornadas adicionais na vida dos operários, para os sindicalistas, o objetivo é obter a contratação de mais trabalhadores e o investimento na fábrica. Este último, considerado a garantia da continuidade da empresa na região e, como proclamam, do emprego. Ao tratar dessa questão, um representante da CF fornece uma síntese mais ampla da prática sindical na gestão:

O jogo tem que ser bom para os dois, não é? É o tal do ganha-ganha [...] os empresários querem que a gente trabalhe cada vez mais ganhando cada vez menos, não é? $\varepsilon$ os trabalhadores querem trabalhar cada vez menos ganhando cada vez mais. Então, muitas vezes, a gente entra com o ponto de equilibrio entre essas duas partes.

Ao se projetar acima das partes, a gestão sindical da empresa se vê como a mais racional para tomar decisões na direção da identidade de interesses entre trabalhadores e capitalistas. Curiosamente, a expressão ganha-ganha (Win-Win) é empregada para atribuir as virtudes do interesse mútuo à chamada produção enxuta e minimizar a autonomia da ação sindical dos trabalhadores (Womack; Jones; Roos, 1990). Um de seus efeitos entre os operários é a ideologia do consenso entre as partes na gestão da fábrica:

Tudo que a firma faz aqui dentro tem o Sindicato no meio. É tudo feito em comum acordo com os dois.

No entanto, a evolução da produção e do emprego na fábrica questiona a ideia de ganha-ganha. De 1988 a 2011, o número de empregados caiu de 20.182 para pouco mais de 12.000 , enquanto a produtivida- 
de saltou de 2,3 para 6,6 veículos/trabalhador. Com isso, igual ou maior magnitude de capital explora uma base menor de trabalhadores; condição que impele o capital tanto ao prolongamento quanto à intensificação do trabalho.

O questionamento também parte dos operários. No contexto da crise de 2009, a empresa pressionou para incluir as jornadas adicionais no $\mathrm{BH}$, e não mais remunerá-las como horas extras, como condição para reduzir as demissões de 1.600 para 800 trabalhadores.

Apesar do apoio do Sindicato, a assembleia dos trabalhadores, em março de 2009, rejeitou amplamente os termos do acordo. Mesmo diante do perigo da perda do emprego, os operários percebem que nem sempre compensa negociar termos que rebaixam suas condições de trabalho. Pois a questão não se limita apenas aos resultados imediatos dos itens negociados, mas, fundamentalmente, à tentativa de enfraquecer sua capacidade de defesa coletiva, e esta, quando atenuada, fortalece o poder e as injunções gerenciais.

Assim, a percepção operária não está isenta nem tampouco é redutível à prática sindical na gestão da empresa. E essa dinâmica está incorporada às categorias de análise e de interpretação da intensificação do trabalho e saúde que apresentamos a seguir.

\section{Ritmo de trabalho: a linha está a milhão e a linha na sua cola}

A caracterização do ritmo de trabalho considera a centralidade da linha de montagem final para o processo de trabalho na montadora. A linha de montagem funciona com variações de velocidade, combinadas com determinada distribuição de tarefas/ postos/trabalhadores, segundo a meta de produção. 0 aumento da velocidade da linha de caminhões, por exemplo, implica a abertura de novos postos com redistribuição de tarefas entre os operários: para uns, retira-se uma única tarefa, enquanto para outros, se mantém as mesmas tarefas:

Era setenta e quatro foi para oitenta e quatro [caminhões], aí aumenta quatro postos. [...] Tirou uma chave geral de um modelo de caminhão, eu só trabalho de um lado [da linha], não preciso ir do outro lado. [Mas] o pessoal que monta a tubulação de ar, não é mexido em nada. O pessoal que coloca lanterna traseira não amarra o chicote. A amarração é feita no posto novo que abre.

Para todos os montadores, ainda que de modo desigual, o aumento da velocidade da linha intensifica o ritmo com reforço do trabalho repetitivo (aumento da quantidade de operações da mesma tarefa) e redução dos microdescansos entre as operações.

Porém, a menor velocidade também resulta na aceleração do ritmo de trabalho. Neste caso, pelo aumento das tarefas e de postos por trabalhador com a redução do número de operários na linha:

se a linha está rodando a quatro [minutos], você só pega uma peça, se a linha está rodando a seis, você tem que cuidar de dois postos.

Portanto, um dia está numa velocidade, no outro dia está em outra, mas cotidianamente a linha está a milhão. Quer dizer, o ritmo de trabalho permanece intenso independentemente da variação da velocidade da linha, um aspecto também constatado pela literatura internacional sobre intensificação do trabalho (Hatzfeld, 2004).

Operários da usinagem, como operadores de máquina, também percebem a aceleração do ritmo de trabalho pela pressão da linha:

É uma média de quarenta a cinquenta peças por turno e o tempo é bem, ali, é bem em cima pra tirar essa produção, e fora a tensão que fica a linha. [...] A semana inteira a linha na sua cola.

O intenso ritmo, sintetizado nas frases a linha está a milhão e a linha na sua cola, pode variar conforme o modelo do produto (eixo, motor, caminhão, ônibus), a frequência ou a sequência em que são fabricados. Na linha, a sequência alternada entre caminhões leves, médios e pesados é alterada em função da demanda: como pede a seção de vendas.

Estamos próximos da característica da intensificação pela combinação simultânea entre exigência industrial, em que o ritmo de trabalho depende de um equipamento automático ou de prazos de produção, e exigência comercial, em que o ritmo de trabalho depende da demanda (Gollac; Volkoff, 2007). Se, como vimos, as exigências industriais 
são suficientes para caracterizar a intensificação, a flutuação da demanda atua na variação de seu grau. Por isso, importa considerar o processo de trabalho na montadora como unidade entre a produção imediata e a circulação na situação concreta do desenvolvimento capitalista no país.

Na última década, o crescimento da produção de commodities agrícolas e minerais e a expansão do crédito à produção e à comercialização impulsionaram a escala de produção e alteraram o perfil da demanda na direção da maior participação dos segmentos de caminhões pesados: passou de $45 \%$ do total da produção, em 2002, para 65,3\%, em 2011 (Anfavea, 2013). Isso acentuou o grau de intensificação do trabalho, pois: de um lado, a redução do tempo de rotação do capital, com o incremento do crédito, recrudesceu as exigências industriais por prazos mais curtos de produção; de outro, a maior frequência da fabricação e montagem de peças maiores para caminhões pesados aumentou as exigências de maior esforço contra a gravidade e postura forçada dos operários em situação de constrangimento temporal.

Além disso, pelas falas, o ritmo de trabalho implica movimentos alternados, irregulares e desiguais segundo a habilidade do trabalhador. Na literatura, a habilidade aparece como exigência gerencial para a aceleração do ritmo (Fernandes; Assunção; Carvalho, 2010). Mas, as falas sugerem ainda um quê a mais, não compreensível em termos de habilidade ou redutível ao exigido e dificilmente explicado pelos operários, pronunciado ora como agilidade, detalhe, jeito ou manha.

A manha é, antes de tudo, vista pelos operários como uma conquista, a astúcia da tentativa de gerir o tempo e o ritmo de trabalho. Mas uma conquista incerta e nunca definitiva, pois seguidamente questionada pelas injunções gerenciais e pelas mudanças de processo ou de produto:

vai inovando a montagem, o trabalho muda, tudo muda. [...] Entrou um caminhão novo, você tem que aprender a montar.

Ou seja, a astúcia operária expressa pelo aprendizado produzido na interface individual-coletivo do trabalhar/defender-se das nocividades do contexto de trabalho.
Esse saber prático do trabalhador possibilita adiantar a produção e obter pausas informais durante a jornada. Trata-se de uma prática comum aos operários, inclusive na linha de montagem. Um dos operários, ao citar os montadores da turma B (ver Quadro 1):

Eles querem arrepiar a produção para parar mais cedo. Então, quando dá dez e quarenta, dez e cinquenta da noite, já acabaram a produção, fizeram a meta. Vão todos pra área de lazer e sentam e vão jogar dominó.

A ação coordenada dos operários expressa uma intensa mobilização biopsicossocial de defesa da saúde para, simultaneamente, escapar do trabalho penoso e realizar atividades lúdicas (jogar, ouvir música, conversar, ler). A pausa conquistada pela autointensificação pode contribuir com a formação de coletivos operários, no sentido de unir os que compartilham uma mesma experiência política e sanitária no enfrentamento das penosidades, e não apenas os que participam das mesmas ações defensivas (Oddone et al., 1986).

Mas, contraditoriamente, a exposição do ganho de tempo permite à gerência aumentar as diligências para expropriar seu fundamento: o conhecimento prático operário. Esses conhecimentos, depois de estudados, selecionados e reelaborados pela gerência, são aplicados em equipamentos, na simplificação de tarefas ou em normas de trabalho.

Portanto, o intenso ritmo de trabalho expressa práticas contraditórias e desiguais, um campo de lutas concernente ao processo de intensificação. Algumas práticas de defesa da saúde alcançadas pelos operários podem assumir um aspecto ardiloso, pois, sem limitar o poder gerencial, preservam o contexto tendente a novas injunções para intensificar o trabalho.

\section{Prolongamento do trabalho: a vida é um filme que não tem intervalo nenhum}

O prolongamento do trabalho corresponde a uma modalidade particular da exploração capitalista relativa à grandeza extensiva do trabalho, por isso, 
distinta da intensificação. Mas, ao mesmo tempo, o prolongamento também constitui uma forma de intensificar o trabalho. É o que analisamos por meio das seguintes práticas: banco de horas e jornada adicional.

\section{Banco de horas}

Na empresa, um regime de compensação de horas similar ao BH foi implantado, ainda no final dos anos 1980, com o nome de "Redução de jornada/ Horas acumuladas", isto é, bem anterior à Lei 9.601 de 1998. Esse regime acompanhou a redução da jornada de trabalho: janeiro de 1996, de 44 para 43 horas semanais, em outubro do mesmo ano, 42 horas e, por fim, outubro de 1999, para 40 horas "em média" (Sindicato dos Metalúrgicos do ABC, 2001, p. 31), quando passou a ser denominado banco de horas.

O termo "em média" adverte para o fato de a jornada de trabalho, combinada ao $\mathrm{BH}$, permanecer acima das 40 horas semanais, como pode ser visto pelo Quadro 1. Essa jornada prolongada constitui a jornada "habitual" ou "normal" dos trabalhadores. As horas a mais são creditadas no BH para futura compensação por folgas individuais e/ou coletivas.

As possibilidades e limites para a utilização da folga são variáveis e desiguais, segundo o setor da empresa, o dia da semana, o saldo no BH e, notadamente, o momento da produção. Com a produção em alta fica difícil dar folga [pois] não tem pessoas reservas. Em momentos de baixa produção, a empresa concede folgas coletivas a uma parcela dos operários. Para estes, esse tempo de não trabalho fora da jornada é vivenciado com insegurança, tensão e ansiedade. Além disso, a folga coletiva permite manter elevado o ritmo de trabalho para quem continua em atividade na fábrica.

Os relatos corroboram características do BH que analisamos em outro estudo (Pina; Stotz, 2011), por isso, não vamos retomá-las aqui. Cabe ressaltar um aspecto, então pouco enfatizado, a saber: a intensificação do trabalho aparece como motivação da folga individual, para o trabalhador simplesmente descansar. Ao mesmo tempo, a folga implica intensificar o trabalho dos demais trabalhadores do grupo:

Quando um cara se afasta é um problema porque os outros ficam sobrecarregados, mas o cara já se afastou porque o ritmo já não está fácil.

\section{Jornada adicional}

A jornada adicional corresponde a uma jornada suplementar, realizada nos finais de semana ou feriados. Sua contratação abrange todos os trabalhadores da empresa por meio de acordo coletivo. 0 Quadro 2 traz a quantidade de jornadas adicionais no período 2008-2011.

\section{Quadro I - Jornada de trabalho e banco de horas na MBB/SBC}

\begin{tabular}{|c|c|c|c|c|c|c|c|}
\hline \multirow{3}{*}{ Turma } & \multicolumn{3}{|c|}{ Jornada de trabalho } & \multicolumn{4}{|c|}{ Banco de horas } \\
\hline & \multirow{2}{*}{ Diária } & \multirow{2}{*}{ Dias da semana } & \multirow{2}{*}{$\begin{array}{c}\text { Horário de } \\
\text { trabalho }\end{array}$} & \multicolumn{2}{|c|}{ Horas acumuladas } & \multicolumn{2}{|c|}{ Compensação das horas } \\
\hline & & & & Diária & Semanal & Positiva & Negativa \\
\hline A & $8 h_{30}$ & $\begin{array}{l}\text { Segunda a } \\
\text { sexta-feira }\end{array}$ & $\begin{array}{c}5 h_{45} \text { às } \\
15 \mathrm{~h}\end{array}$ & 30min & $2 \mathrm{~h}_{30}$ & \multirow{6}{*}{$\begin{array}{l}\text { Limite: } 120 h \\
\text { Folgas } \\
\text { individuais } \\
\text { ou } \\
\text { coletivas, } \\
\text { ou horas } \\
\text { transferidas } \\
\text { para o } \\
\text { próximo } \\
\text { período }\end{array}$} & \multirow{6}{*}{$\begin{array}{l}\text { Horas } \\
\text { transferidas } \\
\text { para o } \\
\text { próximo } \\
\text { período }\end{array}$} \\
\hline B & $8 h_{30}$ & $\begin{array}{l}\text { Segunda a } \\
\text { sexta-feira }\end{array}$ & $\begin{array}{l}15 \mathrm{~h} \text { às } \\
23 h_{58}\end{array}$ & 3omin & $2 \mathrm{~h}_{30}$ & & \\
\hline $\mathrm{N}$ & $8 \mathrm{~h} 30$ & $\begin{array}{l}\text { Segunda a } \\
\text { sexta-feira }\end{array}$ & $\begin{array}{c}7 \mathrm{~h} 45 \text { às } \\
17 \mathrm{~h}\end{array}$ & 30min & $2 \mathrm{~h}_{30}$ & & \\
\hline 1 & $7 \mathrm{~h} 20$ & $\begin{array}{l}\text { Segunda a } \\
\text { sábado }\end{array}$ & $\begin{array}{c}5 h_{45} \text { às } \\
13 h_{45}\end{array}$ & 4omin & $4 \mathrm{~h}$ & & \\
\hline II & $7 \mathrm{~h} 20$ & $\begin{array}{l}\text { Segunda a } \\
\text { sábado. }\end{array}$ & $\begin{array}{c}13 h_{45} \text { às } \\
21 h_{45}\end{array}$ & 4omin & $4 \mathrm{~h}$ & & \\
\hline III & $8 h_{15}$ & $\begin{array}{l}\text { Segunda a } \\
\text { sexta-feira }\end{array}$ & $\begin{array}{c}21 h_{45} \text { às } \\
5 h_{45}\end{array}$ & $15 \mathrm{~min}$ & IhI5 & & \\
\hline
\end{tabular}

Fonte: Sindicato dos Metalúrgicos do ABC (2001). 


\section{Quadro 2 - Jornadas adicionais contratadas na MBB/SBC}

\begin{tabular}{|c|c|c|c|c|}
\hline Jornada adicional & 2008 & $2009^{\prime}$ & 2010 & 2011 \\
\hline Quantidade & 23 & 10 & 25 & 27 \\
\hline
\end{tabular}

[1] Somente entre setembro e dezembro. Os meses anteriores foram de forte queda da produção.

Para os trabalhadores, a jornada adicional intensifica ainda mais o trabalho: de um lado, mantém uma sequência longa ou ininterrupta de dias de trabalho pela exclusão do descanso semanal. Nas falas, a ênfase recai na restrição à vida social e familiar e surge a imagem da vida operária confinada ou aprisionada à fábrica: nós vivemos praticamente a nossa vida aqui dentro. De outro, porque nessas jornadas se trabalha bem mais do que em dia normal ou praticamente o dobro.

Os representantes sindicais ressaltam a cláusula de não obrigatoriedade do comparecimento à jornada adicional. Mas, embora vista como uma brecha, os operários estão cientes de seus limites formais: não é obrigatório, teoricamente. Pois, além de enfrentar a pressão da chefia, a contratação constrange cada trabalhador a compartilhar o excesso de trabalho:

Se eu não for vai sobrecarregar outra pessoa, então eu tenho que ir, não é? Mas não deveria existir jornada extra.

O constrangimento pode, inclusive, calar a voz contrária à jornada adicional pela percepção de pouca permeabilidade do grupo para debater esta possibilidade ou de o comentário ser entendido como política contra a empresa [em que] você acaba sendo o louco. 0 trabalhador permanece no grupo, mas dissimula suas expressões de descontentamento.

Mais do que uma dimensão física ou espacial, o confinamento ou aprisionamento à fábrica denota um processo social de individualização, na tentativa de limitar o horizonte operário à racionalidade da empresa. Perante o enfraquecimento da ação coletiva, o trabalhador individual percebe-se sozinho confrontado às contradições das formas de exploração e dominação suportadas na empresa: "E ele procura assumir estas pressões, persuadido no fundo de si mesmo que são suas próprias insuficiências que tornam sua missão tão difícil e não as contradições inscritas na própria organização.” (Linhart, 2000, p. 34)

O absenteísmo, como dimensão da resistência (molecular) operária, constitui uma dessas contradições. $\mathrm{O}$ absenteísmo expressa a fuga pela privação da vida (temos vida fora daqui), isto é, em função da disponibilidade desmedida do indivíduo para a empresa. Uma fuga efetivada, em boa medida, clandestinamente. Da perspectiva individual, sua amplitude é bastante restrita:

Está tendo muita jornada [adicional], se vocêfaltar muito é um problema. $\varepsilon$, se você ficar totalmente subjugado à empresa, vai ter que tempo?

Por isso, o absenteísmo pode ser entendido como uma forma de resistência individual e "clandestina".

A jornada adicional viabiliza o aumento da produção relativamente ao menor número de operários presentes. Com o maior absenteísmo, sobretudo, nas linhas de montagem, a gerência redistribui os grupos, fixa líderes e revisores em postos na linha e recorre ao empréstimo de operários de outros setores: manter a meta de produção do dia normal à revelia das condições suportadas pelos operários, eis o objetivo imposto pela gerência superior e assim narrado:

Você é pressionado [mas] como é que eu vou fazer o mesmo número faltando a metade? Vou ter de dobrar a capacidade de produção de um homem?

Quer dizer, o trabalhador é tensionado a dar conta das tarefas a mais. Isso tende a remover as "folgas" ("poros") criadas por eles e, ao mesmo tempo, expõe os "problemas" à gerência. Esta, por sua vez, pode criar pressão adicional sobre os operários para sua correção.

Além da obtenção do aumento da produção relativamente ao menor número de trabalhado- 
res, as jornadas adicionais podem constituir um "laboratório" para aperfeiçoar a intensificação do trabalho. A grande quantidade e a frequência das jornadas adicionais durante o ano possibilita à gerência testar diferentes configurações entre grupos, postos e tarefas por trabalhador para ganhar "átomos de tempo", identificar problemas e avaliar a mobilização do trabalhador para dar conta do trabalho a mais em condições de extrema tensão. O estudo e a sistematização dessas experiências pela gerência podem gerar inovações no processo de trabalho com novas exigências aos trabalhadores. Isso sugere pensar a jornada adicional como um laboratório de expropriação/apropriação do aprendizado coletivo operário, que tem o estresse como lógica de gestão.

As práticas de prolongamento representam uma exigência de disponibilidade para se trabalhar mais horas e mais intensamente. Isso afeta drasticamente a qualidade do tempo de não trabalho na e fora da jornada, como sugere a frase na abertura deste tópico: parece que a vida é um filme que não tem intervalo nenhum.

\section{Administração por estresse}

A definição de metas para alcance pelos trabalhadores se tornou um poderoso instrumento de gestão. Da perspectiva dos trabalhadores, relata um representante da CF, as metas adicionam um valor de estresse no trabalho, notadamente por sua vinculação à PLR.

A PLR pode ser considerada uma forma de salário por tarefa, pois seu valor está condicionado a metas de produção preestabelecidas a cada doze meses. $\mathrm{Na}$ empresa, diferentemente dos anos anteriores, os acordos da PLR em 2010 e 2011 excluíram as metas de qualidade e absenteísmo e mantiveram apenas a meta de volume de produção, acentuadamente elevada nestes anos, 73.680 e 80.000 veículos, respectivamente. A motivação, segundo um dos representantes sindicais, implica a PLR como prática de intensificação, uma vez que, se a empresa

está exigindo que o trabalhador trabalhe mais, o absenteísmo vai ser maior. Se o ritmo de trabalho está maior, a qualidade vai ser menor.
Esse relato também manifesta a tentativa de preservar o valor da PLR, considerada pelos trabalhadores e sindicalistas como um $14^{\circ}, 15^{\circ}$ ou até um $16^{\circ}$ salário.

Ao intensificar o trabalho, a PLR amplia a mais-valia e gera esse aumento no preço da força de trabalho, que, todavia, não compensa o desgaste operário (Pina; Stotz, 2011). Inclusive pela ampliação da defasagem entre os momentos da realização do trabalho a mais e do pagamento do bônus, este último realizado duas vezes ao ano. Pois o trabalho mais intenso acontece em jornada diária durante todo o ano, enquanto o preço da força de trabalho pago mensalmente se mantém inalterado, sem acréscimo pelo trabalho adicional. Ou seja, com a PLR os trabalhadores "financiam o capital circulante da empresa com uma fração de seu fundo de subsistência anual" (Cipolla, 2005, p. 621).

Apesar da exclusão do cálculo da PLR, os operários não estão isentos da pressão das metas de qualidade e absenteísmo. Diante do aumento dos indicadores de qualidade (retrabalho e refugo de materiais), a gerência reitera a ameaça da terceirização, como relata um dos operários: a Volkswagen está na nossa cola, se continuar vai terceirizar. A lógica subjacente à PLR é reafirmada: manter a pressão para comprometer os operários com as metas (as metas são nossas, ironiza um operário) na direção da concorrência capitalista, por meio da quebra de vínculos solidários entre os trabalhadores da mesma ou de diferentes empresas.

Nesse sentido, tarefas gerenciais de supervisão encontram-se disseminadas no grupo. Na reunião do grupo, um trabalhador pode ser responsabilizado pela ocorrência de retrabalho ou refugo, mesmo se observar as normas de qualidade. Entre os operadores de máquina, não matar a peça é uma qualidade profissional, um valor, para muitos, faz parte da honra; por isso, é comum reduzir o intervalo de aferição das peças. Essa intensificação, por sua vez, tende a degradar a qualidade do trabalho que afeta a identidade do trabalhador (Davezies, 2007). Como indicamos antes, trata-se de uma condição de penosidade (Linhart, 2011).

Quer dizer, o grupo pode se constituir em fonte de estresse e enfraquecer os vínculos solidários entre os operários, o companheirismo. A ação do grupo 
também se dirige a vigiar atitudes e comportamentos: Olha o seu horário. Oh, vai lavar a mão. Por que você não veio ontem? Ou ainda prevenir situações de conflito com a permanente advertência dos riscos para a avaliação:

Estão me ferrando. [Por isso] só vou produzir X. Mas aí vem o cara: olha o prontuário, hoje está em alta, amanhã está em crise.

A imagem do prontuário pesa sobre cada operário: nele a chefia registra os eventos por ela considerados negativos na avaliação do trabalhador, sem dar-lhe ciência do conteúdo. Entre os operários, prontuário é chamado de capivara, jargão policial para folha corrida, uma ameaça sempre presente e sorrateira: está nas suas costas, mas você não vê.

A avaliação incide na perspectiva de ascensão profissional na empresa, entendida pelos operários como recusa a ficar bloqueado no mesmo posto e para escapar dos setores considerados ruins, notadamente a linha de montagem. 0 mesmo sentido foi observado no estudo de Beaud e Pialoux (2009).

Mas, a estrutura ocupacional da empresa não absorve o grande número de operários com formação universitária ou pós-graduação, muitos deles na linha, e os anos de permanência na mesma atividade vão restringindo os sonhos. Isso tanto para os operários com maior ou menor tempo de trabalho na empresa. 0 trabalho na montadora passa a ser percebido como transitório, com a perspectiva de busca de carreira profissional fora da empresa; todavia, com poucas chances de concretizar-se. Esse contexto, segundo os representantes sindicais, conforma um ciclo da frustração, associado ao sofrimento e ao adoecimento. E, ainda segundo os sindicalistas, ao representar sua condição como transitória, o trabalhador perde a identidade como operário e se afasta da organização sindical no local de trabalho.

No entanto, uma possibilidade diferente pode ser pensada a partir das falas dos trabalhadores como, por exemplo:

Trabalhei em diversas áreas, porque eu contestava muito. Eu queria mudanças, dizia que não, não estava certo. [...] Querem quanto mais se produza com menos pessoas, não é? E, aliás, essa é uma forma que tem de avaliação, para você construir um plano de carreira aqui dentro. $\bar{\varepsilon}$ aquele que se submete a esse tipo de produção é quem tem o destaque [...] prejudicando a própria saúde. $E$ ciente disso eu não fazia, respeitava o meu limite, não é? Fazia dentro do meu tempo.

A competição pela promoção se apresenta ao trabalhador como uma exigência gerencial. E a perspectiva de realização profissional fora, de certo modo, expressa um distanciamento da racionalidade da empresa, o que possibilita a abertura para práticas de proteção da saúde, passíveis de pautar a ação coletiva.

Os sentidos do distanciamento ou da recusa operária em termos de ação coletiva são eclipsados pelos sindicalistas, inclusive vistos como um obstáculo. No entanto, eles são um problema para a gerência, justamente por afastar o trabalhador do perfil valorizado pela administração por estresse (Pina; Stotz, 2011). 0 distanciamento não isenta o trabalhador do contexto gerador dos problemas à sua saúde. Pelo contrário. Este está sujeito a seguidos empréstimos pela fábrica, muitas vezes, considerado como baixa performance e ameaçado de demissão: cara emprestado é filho sem pai.

No chão de fábrica, baixa performance ficou popularizada como pena preta. Essa expressão é recente; sua difusão está relacionada ao contexto da crise de 2009, que resultou na demissão de 1.600 trabalhadores, como dissemos antes, apesar da resistência operária. Entre os demitidos estavam trabalhadores aposentados e os avaliados como baixa performance.

Esse processo compreendeu inclusive a participação sindical na análise nome a nome dos operários relacionados para demissão. Para alguns, a demissão foi revista, para outros, não. É o que relata um dos sindicalistas:

A pessoa já teve duas, três, quatro chances, não é? No momento não teve como segurar mesmo. Era um momento que tinha que ter alguma [demissão].

Como noção prática, a noção de responsabilidade (Markert, 1994) interpela a gestão sindical para classificar cada trabalhador pelos compromissos assumidos para viabilizar os acordos com a empresa: 
A gente cobra que a Mercedes gere emprego de qualidade. [...] Então se a gente tiver aqui dentro trabalhadores que não levam o trabalho a sério, também vai colocar essa relação, tá? O nosso emprego em risco.

Essa perspectiva sindical permite uma aproximação aos parâmetros da avaliação de desempenho da empresa.

Agora, independentemente dos motivos desencadeadores da demissão - queda da produção, crise, turnover -, os trabalhadores demitidos são, cada vez mais, identificados como os de baixo desempenho. Entre seus efeitos, a legitimação do processo de individualização e responsabilização do próprio trabalhador por sua demissão (Linhart, 200o): ele não se empenhou mais no trabalho, não se colocou disponível para trabalhar mais horas e ainda mais intensamente. 0 trabalhador sai da empresa e a marca de pena preta segue com ele para além dos muros da fábrica, se estende aos familiares e às relações sociais (vizinhos, igreja, comércio, escola dos filhos).

A administração por estresse (Parker; Slaughter, 1995), ou seja, o estresse como lógica gerencial, estrutura e orienta as práticas implicadas no desempenho. 0 estresse requer a mobilização do trabalhador para viabilizar os resultados e continuamente disponibilizar seu conhecimento prático. Isso é significativo para a gestão avaliar suas competências, que são centradas mais nos meios mobilizados pelo trabalhador do que apenas nos resultados.

Por sua vez, o distanciamento do trabalhador em relação à gestão por estresse e suas implicações na saúde expressam contradições do processo de intensificação do trabalho. Seu entendimento se faz inseparável das condições históricas e das formas como coletivamente os operários experimentam e diferenciam seus contraditórios aspectos.

\section{Considerações finais}

Neste estudo, apreendemos o processo de intensificação do trabalho e saúde, a partir das maneiras como os operários da empresa o experimentam, especialmente ao assinalar como as práticas de exploração e expropriação, ritmo de trabalho, prolongamento do trabalho e administração por estresse confrontam a capacidade coletiva do trabalhador.

Ressaltamos uma característica relativa ao enfraquecimento da dimensão coletiva. Trata-se da penosidade produzida pelas categorias analisadas, especialmente, pelas práticas de administração por estresse, orientadas para a vigilância de atitudes e comportamentos contrários à norma e à cultura da empresa. Também para prevenir conflitos no cotidiano de trabalho ou tentar definir como e onde estes conflitos podem se expressar pela sistemática difusão do aviso de perigo: um descuido do operário pode ser prejudicial ao desempenho e à avaliação, o que se configura em uma ameaça de não ascensão profissional e, no limite, de demissão. É preciso atenção e autocensura de atos, gestos, atitudes, palavras também junto aos colegas de trabalho e não mais apenas perante a hierarquia. Isso conduz a sensação de não poder relaxar. Tanto mais quando as seguidas injunções gerenciais para redefinir e intensificar o trabalho, além de não contrapostas, são, pelo contrário, ativamente corroboradas pelo grupo ou por representantes sindicais. Toda essa estrutura disciplinadora expandida foi assim manifesta: Isso cansa!

Aqui, cabe indicar que, como disse Simone Weil (1979, p. 103), "este cansaço precisaria de um nome à parte”. A autora expressou o cansaço físico e mental na interseção entre a fadiga, o medo e a angústia vivenciados pelo trabalhador: o despotismo gerencial na imposição do ritmo, o medo de não acompanhar as cadências, de "matar" peças e das "broncas", a angústia na ida e na volta do trabalho. Em síntese: fadiga, medo e angústia onipresentes.

Além dessas dimensões, no caso estudado, chamamos atenção para um tipo diferente de cansaço. 0 que está subjacente a ele é o sofrimento pela perda, o enfraquecimento ou a ausência dos companheiros (capacidade coletiva), ao não encontrar ou sentir suas posições reafirmadas no momento em que cada trabalhador é confrontado pelas injunções gerenciais, vendo-se atado e calado por essa estrutura disciplinadora, o que resulta na redefinição do exercício de seu trabalho e em sua intensificação.

É essa ausência dos companheiros, sentida como onipresente no tempo e no espaço, que está no cen- 
tro das manifestações de sofrimento implicadas nas práticas de intensificação do trabalho. E que, quando não enfrentadas coletivamente, devem ser suportadas pelo indivíduo.

O avanço do domínio da fábrica sobre as posições antes conquistadas pelos operários, assim como a perda parcial dos instrumentos de resistência coletiva gerados ao longo das lutas operárias, é uma dimensão incorporada à noção de "envelhecimento social" (Beaud; Pialoux, 2009). A tristeza velada, o cansaço, a angústia quanto ao futuro ou a decepção multiforme são algumas de suas expressões. Mas, para os autores, essas manifestações marcam a trajetória dos operários mais antigos relativamente aos novos. Com isso, Beaud e Pialoux introduzem uma conotação de conflito entre gerações e limitam o emprego da noção de envelhecimento social para a presente pesquisa, pois, neste estudo, o enfraquecimento da capacidade coletiva não está determinado pela suposição de disputas entre gerações.

O estudo da intensificação do trabalho e saúde interroga e põe em relevo a dimensão coletiva do trabalhador na luta pela saúde, e está a merecer outras investigações pela Saúde Coletiva/Saúde do Trabalhador. Esta problemática pode ser abordada pelo detalhamento das diferenças entre os dois grupos participantes desta pesquisa: trabalhadores diretos e sindicalistas. Perspectivas distintas entre esses dois grupos em relação à dimensão coletiva e à intensificação do trabalho e saúde podem ser inferidas, mas não foi nosso propósito discuti-las, suas diferenças não foram suficientemente exploradas nesta pesquisa; estão, contudo, difusas ao longo do texto.

Na medida em que prioriza a manutenção do emprego, a participação sindical na gestão da empresa estabelece pontos de contato com a lógica da administração por estresse e confronta a independência política dos coletivos de trabalhadores na proteção e no questionamento da determinação dos problemas de saúde.

Entre os trabalhadores diretos, predomina a ambiguidade entre a maior aproximação e a contestação aberta à racionalidade gerencial. Esta ambiguidade também expressa a natureza antagônica do processo de trabalho e, portanto, contém a crítica do ponto de vista das condições mais imediatas dos operários. Algumas manifestações de resistência operária, como a autointensificação, o absenteísmo e o distanciamento das práticas gerenciais, podem e são confrontadas ou apropriadas pela própria administração por estresse na direção da reprodução das práticas de intensificação do trabalho. Tanto mais quando essas experiências permanecem difusas e não são sistematizadas pelos coletivos operários.

O coletivo não se limita a sistematizar as experiências em termos dos efeitos das práticas mais imediatas dos trabalhadores, mas deve fazê-lo após distinguir seus diferentes e contraditórios aspectos, sem se furtar aos desafios de estabelecer a conexão lógica e histórica com as determinações mais profundas do processo de trabalho e saúde na formação econômica social brasileira.

A partir do caso estudado, acreditamos contribuir para o avanço do entendimento da intensificação do trabalho e saúde e, ao mesmo tempo, trazer indicações sobre os limites e possibilidades postos à ação coletiva dos trabalhadores nas atuais condições históricas.

\section{Referências}

ASKENAZY, P. et al. (Org.). Organisation et intensité du travail. Toulouse: Octarès, 2006.

ANFAVEA - ASSOCIAÇÃO NACIONAL DOS FABRICANTES DE VEÍCULOS AUTOMOTORES. Anuário da indústria automobilística brasileira 2011. São Paulo, 2011. Disponível em: <http://www. virapagina.com.br/anfaveazo11>. Acesso em: 8 jul. 2014.

ANFAVEA - ASSOCIAÇÃO NACIONAL DOS FABRICANTES DE VEÍCULOS AUTOMOTORES. Anuário da indústria automobilística brasileira 2013. São Paulo, 2013. Disponível em: <http://www. virapagina.com.br/anfavea2013/files/anfavea2013. pdf $>$. Acesso em: 8 jul. 2014.

BARTOLI, M.; ROCCA, M. Gestion par objectifs et réquisition de compétences: vers de nouvelles sources d'intensification du travail? In: ASKENAZY, P. et al. (Org.). Organisation et intensité du travail. Toulouse: Octarès, 2006. p. 21-28. 
BEAUD, S.; PIALOUX, M. Retorno à condição operária: investigação em fábricas da Peugeot na França. São Paulo: Boitempo, 2009.

BOURDIEU, P. A miséria do mundo. Petrópolis: Vozes, 1999.

BRESCIANI, L. P. O contrato da mudança: a inovação e os papeis dos trabalhadores na indústria brasileira de caminhões. 2001. Tese (Doutorado em Política Científica e Tecnológica) - Instituto de Geociências da Universidade de Campinas, Campinas, 2001.

CIPOLLA, F. P. Os limites da participação dos trabalhadores nos ganhos das empresas. Revista de Economia Política, São Paulo, v. 27, n. 4, p. 616632, 2007.

DAL ROSSO, S. Mais trabalho: a intensificação do labor na sociedade contemporânea. São Paulo: Boitempo, 2008.

DAVEZIES, P. Intensification: danger: le travail rétréci. Santé et Travail, Paris, n. 57, p. 30-33, janv. 2007.

DIEESE - DEPARTAMENTO INTERSINDICAL DE ESTATÍSTICA E ESTUDOS SOCIOECONÔMICOS. o perfil do trabalhador metalúrgico do $A B C$. São Bernardo do Campo, 2011. Disponível em: <http://www.smabc.org.br/ Interag/temp_img/\% 7B6A7oBDBD-9FF64A81-B37E-37E9DA237913\%7D_Perfil\%20 Metal\%C3\%BArgicos\%20-\%2obase\%2oSMABC_ R10\%20-\%2otexto\%2ojul11_Revisado.pdf $>$. Acesso em: 7 jul. 2014.

DERRIENNIC, F.; VEZINA, M. Intensification du travail et répercussions sur la santé mentale: arguments épidémiologiques apportés par l'enquête ESTEV. In: ASKENAZY P, et al. (Org.). Organisation et intensité du travail. Toulouse: Octarès, 2006. p. 327-333.

FAIRRIS, D.; BRENNER, M. Workplace transformation and the rise in cumulative trauma disorders: is there a connection? Journal of Labor Research, Fairfax, v. 22, n. 1, p. 15-28, 2001.

FERNANDES, R. de C. P.; ASSUNÇÃO, A. A.; CARVALHO, F. M. Tarefas repetitivas sob pressão temporal: os distúrbios musculoesqueléticos e o trabalho industrial. Ciência \& Saúde Coletiva, Rio de Janeiro, v. 15, n. 3, p. 931-942, 2010.

GOLLAC, M.; VOLKOFF, S. Les conditions de travail. Paris: La Découverte, 2007.

HATZFELD, N. L'intensification du travail en débat: thnographie et histoire aux chaînes de Peugeot-Sochaux. Sociologie du Travail, Paris, v. 46, n. 3, p. 291-307, 2004.

LINHART, D. Entrevista: Danièle Linhart.

Trabalho, Educação e Saúde, Rio de Janeiro, v. 9, n. 1, p. 149-16o, 2011.

LINHART, D. O indivíduo no centro da modernização das empresas: um reconhecimento esperado, mas perigoso. Trabalho \& Educação, Belo Horizonte, n. 7, p. 24-36, jul./dez. 2000.

LOPES, J. S. L. A tecelagem dos conflitos de classe na cidade das chaminés. Rio de Janeiro: Marco Zero; Brasília, DF: UnB: MCT/CNPq, 1988.

MARKERT, W. "Lean production": uma revolução na forma de produção capitalista. Educação \& Sociedade, Campinas, v. 49, p. 362-39o, dez. 1994.

MARX, K. O capital: crítica da economia política. São Paulo: Abril Cultural, 1984 (Coleção Os Pensadores. Livro 3, Tomo 1).

ODDONE, I. et al., (Org.). Ambiente de trabalho: a luta dos trabalhadores pela saúde. São Paulo: HUCITEC, 1986.

OLIVEIRA, R. C. de. O trabalho do antropólogo. Brasília: Paralelo 15; São Paulo: UNESP, 2000.

PARKER, M.; SLAUGHTER, J. Unions and management by stress. In: BABSON, S. (Org.). Lean work: empowerment and exploitation in the global auto industry. Detroit: Wayne State University, 1995. p. 41-53.

PEREIRA, V. M. C. O coração da fábrica: estudo de caso entre operários têxteis. Rio de Janeiro: Campus, 1979.

PINA, J. A.; STOTZ, E. N. Participação nos lucros ou resultados e banco de horas: intensidade do trabalho e desgaste operário. Revista Brasileira de Saúde Ocupacional, São Paulo, v. 36, n. 123, p.162176, 2011. 
PINA, J. A.; STOTZ, E. N. Intensificação do trabalho e saúde do trabalhador: uma abordagem teórica. Revista Brasileira de Saúde Ocupacional, São Paulo, v. 39, n. 130, p. 150-16o, 2014.

SINDICATO DOS METALÚRGICOS DO ABC. Acordos coletivos entre o Sindicato dos Metalúrgicos do ABC e a Mercedes Benz do Brasil
S/A. São Bernardo do Campo, 2001.

WEIL, S. A condição operária e outros estudos sobre a opressão. Rio de Janeiro: Paz e Terra, 1979. WOMACK, J. P.; JONES, D. T.; ROOS, D. The machine that changed the world: the story of lean production. New York: Rawson Associates, 1990.

\section{Contribuição dos autores}

Pina é responsável pela definição do planejamento, realização da pesquisa e pela redação do artigo. Stotz participou da orientação geral da pesquisa, contribuiu na estruturação e na revisão do manuscrito.

Recebido: 13/03/2014

Reapresentado: 10/07/2014

Aprovado: 04/08/2014 